\title{
A Strategic Approach for Manufacturers Facing Mandated Change
}

\author{
Arthur J. Noetzel \\ John Carroll University \\ Cleveland, Ohio \\ John M. Burnham \\ Tennessee Technological University \\ Cookeville, Tennessee
}

Introduction

In the 1950's and 1960's, the U.S. economy benefitted from a strong rise in productivity. New and improved machinery, better production methods, and huge untapped domestic markets made it possible for American companies to increase and improve output, while holding down costs. Profits increased and workers' wages rose. Many U.S. manufacturing firms became complacent.

During the past fifteen years, however, growth in productivity has collapsed. The days when U.S. companies had a near-monopoly on the domestic market and on mass-production technology are gone forever. American industry is now in the midst of a dynamic and broad-based change, which will fundamentally alter the ways corporations are managed.

Many elements of this drastic transformation of industry are well-known:

a. the gathering force of information technologies;

b. the globalization of industrial markets and the formations of cartels like OPEC;

c. the ongoing wave of mergers, takeovers, and restructuring;

d. the complex shifts in regulatory environments;

e. the breakdown of traditional labor-management relationships;

f. the shortening of product life cycles;

g. the rising expectations of customers; and

h. the fragmentation of many markets.

\section{Mandated Change}

The transformations in industry brought many manufacturers face to face with mandated change. Mandated change arises from the external environment of a business; it is a change which upsets the well-established balance between a firm's resources and prospective opportunities. Such changes render useless other internally generated goals, and mandate new goals imposed by the competitive environment. Mandated change can threaten the survival of a manufacturing business.

Mandated change is not satisfied by simple efforts to improve productivity. Too often these approaches pare down labor costs and make factory workers more efficient, but simultaneously hinder innovation and alienate workers. Mandated change requires more than a short-term fix [20]. It calls for new strategic thinking and the development and 
nurturing of new shared values. It commands that top management manage from the "outside-in" rather than from the "inside-out" [13]. Further top management must recognize the difference between their perception of the change and the essential actuality of the change.

Imposed changes present manufacturing management with an important dilemma in the relationship between productivity and organizational change: the paradox of instability in the midst of stability [1]. In the past, too often, manufacturing was taken for granted; it was accepted as a "given" in the formulation of strategy. It was assumed that manufacturing operated in a closed system, insulated from extemal forces. It was the task of the plant managers to eliminate perturbations and to enhance stability of production. Manufacturing was perceived to be embedded in rigid physical structures with technical details and routine decisions. It was seen as the substratum upon which the dynamic, broad, exciting strategies of finance and marketing rested. "Good manufacturing operations" were believed to be merely the achievement of low costs and high efficiency.

In times of intense competition, manufacturing cannot be taken for granted in the formulation of strategy. It should not be separated or isolated from strategy formulation and implementation in other functional areas. Manufacturing is the translation of the ideas from research and development into products, whose standards of quality, cost, availability, and customer service are equal or surpass the standards set by the most rigorous competitors in the international market. This translation is not so much the production of innovative, breakthrough products as it is a matter of continuous improvement in process-and product-technology integrated with the effective utilization of human resources and with a keen and active understanding of the wants of customers and their buying behaviors.

Change created by the external environment of a firm, however, demands that organizations be adaptive and creative. Goals set in the marketplace by customers and competitors call for organizations that are flexible, innovative, and seeking continuous improvement. Adaptability, creativity, flexibility, and innovation are human attributes. These cannot be assigned to a special segment in an organization. They must be active in all operations from the receipt of raw materials to the delivery of the finished product and post-sales service. Maintaining competitive advantage in the time of mandated change requires a sharp and steady focus on the marketplace simultaneously with a flexibility that permits change in style, attitude, control, and performance methods.

Manufacturing firms seeking both focus and flexibility are finding that four factors are important in building competitive advantage:

a. a keen perspective of markets targeted [19];

b. a recognition that the use and conservation of time [6] and the widespread sharing of information [18] are key resources of the firm;

c. a new orientation toward human resources, organization, and culture of the company; [22] and

d. an integrated, proactive manufacturing strategy [10]. 
Many manufacturing companies have not recognized these factors, because the transformations in American industry have affected different industries and different companies in a variety of ways. Some found that their environmental scanning had been weak or incomplete; signals of change were not seen or understood. Others could not believe that discontinuity could occur because they viewed the future as a continuing extrapolation of past trends. Some were trapped by narrowly defined markets, products, and competition. Still others found they had neither the resources nor the will to respond effectively to world-class competition and worldwide markets. Many manufacturers faced new forces in the external environment which they had never before experienced. Too many failed to recognize that changes had been mandated.

Faced with the dual aspects of mandated change in American industry-the perception of the change and its actuality-business reacted in one of four generic modes [2]:

a. shock: so disturbed as not to be able to shake out of its provincialisms, unable to unlearn the habits of the past, and incapable of reducing bureaucratic rigidity.

b. retreat: to flee to an available, protective market niche.

c. survival: to shrink to the core of the business - what it does best - and to try to cope by reassessing the environment, learning new lessons, and by keeping spirits high.

d. challenge: to create a new vision of the mission of the business and to apply new perspectives and ideas; to stretch the usual bounds of strategy formulation and implementation.

The firms in each of these categories lost degrees of strategic freedom [15]. All learned that the ability to adapt to externally imposed goals is critical for survival. The managements of companies in the first two categories wrapped themselves in a "code of silence," suffered from "the denial syndrome," became excessively cautious, and could not muster the intention to compete. Only the firms in the last two categories were willing to face the struggle of adaptation to mandated change, either reactively or proactively.

\section{Threat of Discontinuity}

Mandated change brings the threat of discontinuity into the marketplace. The nature of this threat may be visualized by the following Venn diagram (Figure 1) representing a firm's competitive advantage before a discontinuity begins [3]. The configuration of the three circles is a visualization of the judgment of the manufacturer concerning its competitive advantage. It is an abstract illustration, not a map with precision. Since a manufacturer facing mandated change is more concerned about the impact of future competitive interactions than about the starting position of competitive forces, the initial Venn diagram may be sketched arbitrarily. Three overlapping circles with equal radii and equidistant centers may be drawn under the assumption of, at least, momentary equilibrium among the competitive forces. The manufacturer will be more interested in the movement of the circles than in their original position (Figure 2). 


\section{Figure 1}

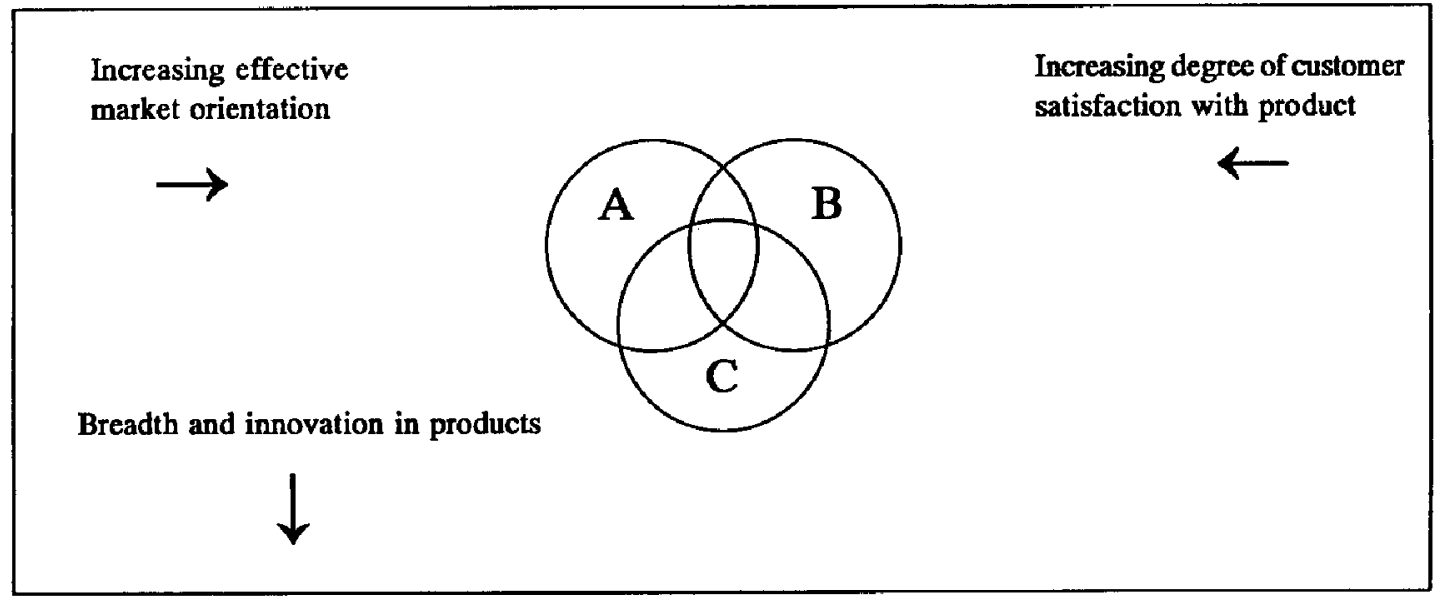

Figure 2

\section{Some Examples of Movement in Competitive Space}

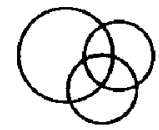

A strengthens distinctive competencies (increases diameter)

$B$ and $C$ unchanged

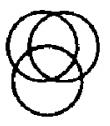

A strengthens market orientation (moves to the right)

$B$ and $C$ unchanged

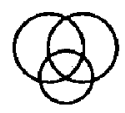

$A$ and $B$ unchanged

C tightens benchmarks (reduces diameter)

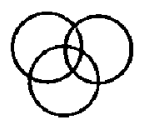

$A$ and $C$ unchanged

B shifts loyalty away from A's products (moves to the right)

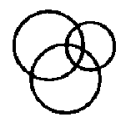

$A$ and $C$ unchanged

B tightens the specifications of its needs (reduces diameter)

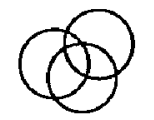

A increases rate of new product development (moves down)

$B$ and $C$ unchanged 
The three overlapping circles are in a region bounded by the dimensions of customer expectations and of the competitive standards of quality, cost, availability, and customer service. This region is the field of competitive interactions and may be termed competitive space; it is abstract construct of the marketplace.

In the diagram, Circle A symbolizes the attributes of the manufacturer and its product. The diameter of the circle represents the strength of the manufacturer's distinctive competencies. The stronger these competencies and skills and the more they directly relate to the changing critical success factors of the industry, the larger will be Circle A. Whether the manufacturer follows a niche strategy (a narrow target market) or has a broad target market, or whether it follows a strategy of overall low cost leadership or one of differentiation [16], the diameter of Circle $A$ is a sign of the company's competitive strength. It should be noted that the diameter of Circle A moves in a manner opposite to that of the diameters of the other two circles.

Circle B pictures the customers' satisfaction in terms of the quantity, quality, price, availability, and customer service provided by the manufacturer. Its diameter is set by specificity of the customers' needs and wants. As the customers become more demanding of the manufacturer, as their needs and wants are presented with increasingly tight specifications, Circle $B$ becomes smaller, its diameter narrows.

Circle $\mathrm{C}$ represents the benchmarks set by major competitors. As competitive standards increase and benchmarks tighten, this diameter will become smaller.

The hatched area, the area common to the three circles, represents the manufacturer's competitive advantage. In this area, the manufacturer's distinctive competencies and the attributes of its product satisfy customer needs and wants and simultaneously equal or surpass the benchmarks for quantity, quality, availability, service, and price set by major competitors.

The dynamics of the marketplace, the forces of competition [17], can cause each circle to move horizontally and vertically. Circle $A$, the manufacturer, may move to the right as it strengthens its market orientation and increases customers' satisfaction. Circle A may move downward as the manufacturer successfully broadens its product line and develops new products. Circle B, the customers, may move to the right, away from the manufacturer, with a shift toward substitute products and decreased loyalty to the manufacturer's products. Of course, Circle B can also move to the left, into the manufacturer's territory, with a growth in loyalty toward the manufacturer's products or with less willingness to accept substitute products from competitors of the manufacturer. But this move would not pose a problem to the manufacturer, but to the competition! Circle B may move downward as customers gain competitive leverage, greater bargaining power into the market. Circle $\mathrm{C}$, the competition, moves to the right as competitors make advances in product or process technology favorable to the customers. Circle $\mathbf{C}$ may move downward as key rivals of the manufacturer launch an attack on the manufacturer's market position; competitive intensity increases.

Thus, there are three movements within the configuration of the three circles: horizontal, vertical, and in the size of the diameter of the circles. If Circle $\mathrm{A}$, the manufacturer, does not move either horizontally, or vertically, and maintains the same level of com- 
petitive strength (the diameter), while either of the two other circles moves to the right or downwards, the hatched area grows smaller and the manufacturer loses competitive advantage. If none of the circles move horizontally to the right or downward, but if competitive benchmarks become tighter or if customer standards of need satisfaction become more specific, again the hatched area of the manufacturer's competitive advantage grows smaller.

The movements of Circle $\mathbf{B}$ and Circle $\mathbf{C}$ may be gradual or abrupt, but the manufacturer, Circle $A$, must recognize the movement. Unless the manufacturer has a strong market orientation and an ongoing capacity to meet competitive benchmarks, there is the threat of a fracture between the circles. The movements of the circles, B and C, and the changing length of their diameters are signals of mandated change. In the face of the threat of a fracture, of complete discontinuity, the manufacturer must give up degrees of freedom in its strategy formulation and must accept the norms imposed upon it by customers and competition.

The threat of discontinuity, the danger of losing profitable participation in the marketplace, arises because manufacturers ignore one or more of the building blocks of competitive advantage - targeted markets, effective use of time and information as resources, vigorous development of human resources, and a proactive manufacturing strategy. This threat may precipitate a crisis following this scenario:

a. The perspective of top management becomes increasingly distorted and increasingly blind to the external environment.

b. Top management focuses upon operational corrections and on the internal environment of the firm and gives less attention to customers and general trends affecting demand.

c. Top management's attention shifts to short term needs, cutting costs, and reducing assets.

d. The emerging crisis causes some stakeholders, such as key suppliers or creditors, to desert the firm.

e. The firm's resources become more constricted and constrained.

\section{Defenses Against Discontinuity}

The strategic alternative to such an inwardly-focused crisis scenario lies in having defenses against the threat of discontinuity. These defenses are skill in scanning the external environment of the firm, in tracking industry trends and competitive forces, and in maintaining strategic "momentum,"-the ease and flexibility of adapting to environmental changes [11]. When a manufacturer is weak in these defenses or is complacent about its position in the marketplace, it also is unprepared for the threat of discontinuity and the concomitant decline in competitive advantage. It fails to see that its survival is in jeopardy. It does not have a clear realization that it must accept changes mandated by the environment which, in turn, mean that the firm must accept externally imposed goals. 
The threat of discontinuity shows that competitive advantage can be lost. Resistance to or denial of mandated change will not restore competitive advantage: The threat of discontimuity tells that competitive advantage is the key to success over an extended period of time and that it can be built, maintained, and enhanced by [21]:

a. providing value to customers;

b. matching uniquely a company's resources and opportunities;

c. crafting the advantage so that it is not easily copied or imitated by competition;

d. founding it on the best industry practices worldwide;

e. giving continuous, ongoing renewal to distinctive competencies;

f. providing effective direction and motivation for the entire organization; and

g. propelling the company toward a truly integrated strategy.

One of the impacts of mandated change is to push competitive advantage with its complex and multiple dimensions to the forefront of management thinking.

The American tire industry faced mandated change. Since 1979, domestic tire companies closed fifteen plants in the United States. By 1987, foreign tires represented 25 percent of the market, an increase in market share of 14 percent in seven years. The demand for the industry's key product, bias-ply tires, declined 75 percent in ten years. Using a new technology, radial tires had attained a threefold increase in service life.

Cooper Tire, the world's fourteenth largest tire company, aggressively sought to gain competitive advantage while in the midst of threatening environmental changes. It did not fall into a crisis mode of management. It moved forward by:

a. improving customer service;

b. enhancing its computer applications to new product development, design, and manufacturing;

c. modernizing and expanding its production facilities;

d. intensifying employee training programs at all levels; and

e. introducing four lines of high performance tires specifically fitted to various segments of its customer market [8].

At Xerox Corporation, the original reprographic product patents were running out in the mid-Seventies. The dominance once held by their copier products was being successfully challenged by a number of domestic and international competitors, each intent on the enormous market Xerox had developed. Xerox market share was dropping dramatically. Indeed, discontinuity had occurred, and Xerox was in danger of losing contact with its customers. Following a study of the situation, it was determined by objective comparisons that Xerox was far from being competitive in any of the key performance areas that were vital to survival.

David T. Kearns, Xerox CEO, announced the theme "Leadership Through Quality" (LTQ) and set as his three goals: "breaking down the functional barriers between groups; concentrating on the customer, and providing customer satisfaction" [14]. LTQ's two 
emphases were customer development and bringing suppliers up to world class quality standards. Improvement in supplier-quality was important because 80 percent of manufacturing cost pertained to purchased parts and components.

At first, Xerox refused to accept the notion that its copier family was not competitive in the global marketplace. It suffered from "the denial syndrome." Following the catharsis of facing hard evidence to the contrary, Xerox responded. In 1980, Xerox adapted the idea of competitive benchmarking and sought internal performance standards tightly correlated to externally imposed performance targets. It then underwent a massive reeducation of suppliers and employees at all levels. Six years after its acceptance of externally imposed goals, Xerox was regaining market share, had reduced its costs, halved its inventory, reduced external lead-times by two-thirds, improved the quality of supplier parts, and cut equipment defects to one-eighth of their 1980 levels [9].

Taking the benchmarks as current targets, Xerox asserts that "If we don't happen to the best in a particular area, everyone will know that we're making a hard run at it [5]."

In terms of the Venn diagram, Cooper Tire moved to the right by improving customer service and moved downward by the introduction of four new lines of tires. It increased its diameter, the symbol of distinctive competencies, by an improved information system, modemized efficient plants, and by a very strong emphasis upon management and employee training and development. In a similar manner we may interpret Xerox's strategic moves as a horizontal move to the right when it began focusing upon the customers and their satisfaction. Much of its efforts were devoted to increasing the diameter of Circle A to overlap competitor benchmarks (Circle C).

Many suppliers to the automotive industry in the United States face mandated change - the threat of discontinuity. Automobile companies have been tightening their standards for quality, cost, and delivery time. In their streamlining, the automobile companies are seeking longer-term contracts with fewer supplier companies and requiring them to provide higher quality items at lower costs; they want "total system suppliers." These are suppliers who fully understand their products and processes, efficiently design and develop new products, control the quality and cost from raw materials to finished product, and deliver the complete assembly on time. Some of the smaller suppliers may be at a disadvantage compared to larger firms in terms of carrying out research and development and in engineering their products. On the other hand, smaller suppliers may have the advantages of flexibility, innovation, adaptability, and strong leadership. "However, in order to survive in the very severe competitive environment, it is most important that they utilize their advantages to the fullest and also that they modify their organizations so as to meet the new car makers' requirements" said Masanobu Myamoto, head of the purchasing division at the Mazda assembly plant in Flat Rock, Michigan [12]. Myamoto's challenge to an automotive supplier is to strengthen distinctive competencies (increase the diameter of Circle A) while customers set more rigorous product specifications (a narrowing of the diameter of Circle B) and while competitor's establish higher benchmarks (decreasing the diameter of Circle C). 


\section{An Initial Assessment}

The first step in building a defense against the threat of discontinuity is an "here-andnow" assessment of the position of the manufacturer and its products in the marketplace. Current competencies and resources must be evaluated for strengths and weaknesses in terms relative to customer satisfaction and competitors' benchmarks. Companies in the mode of shock or retreat from mandated change will hesitate to make such an assessment. A judgment concerning current competitive advantage must be made, - honestly and with integrity, and not with resistance, denial, or rosy optimism - if there is to be a close correlation between internal standards of performance in manufacturing and distribution and the externally imposed norms of excellence.

Manufacturing companies must probe the total current and prospective resources and capabilities to find potential sources of competitive strength. What are our present competitive strengths? How large is the hatched area in the Venn diagram? How fast is the size of the hatched area waning? What are the bases of our current advantages in the marketplace? How well do we understand our customers' needs, their loyalty to us, and the shifting patterns of need in the future? How fast are our customers streamlining their operations and tightening their specifications? In which areas bave competitors established superior benchmarks pertaining to quality, service, delivery time, and cost? What is the rate of improvement competitors are achieving for these benchmarks? Are there signs of weakness or strain in the competitive positioning of our key rivals?

The following simple form (Figure 3) may assist in assessing the manufacturer's competitive position. The form has a major limitation; it is time-static. It is simply a single frame from the motion picture of the market. As such, the assessment should be regularly repeated, to discover rates of changes in customer and competitor actions. More detailed and analytic approaches to the evaluation of the relative lengths of the diameters of the circles in the Venn diagram (Figure 1) are Benchmarking [4] and Quality (Function) Deployment [7]. These approaches facilitate the development of internal goals that match those mandated externally.

The assessment of competitive position will moreover be pointless unless it is immediately followed by a strong, positive commitment to formulate and to carry out a wellconceived strategy with a thrust toward improvement. The initial assessment is but a first step. To be useful to the manufacturer, it must galvanize the organization, as a whole, to effective action. The first steps must be quickly following by a well-articulated statement of intentions for improvement.

Mandated change challenges each manufacturer to judge the size of the hatched area in the Venn diagram (Figure 1), to assess whether the area is growing or shrinking, and express powerfully and clearly to all within the organization its commitment to enlarge it in the face of worldwide competition. 
Figure 3

\section{Assesment of Internal Performance Standards}

\begin{tabular}{|c|c|c|c|c|c|c|}
\hline \multirow[t]{2}{*}{$\begin{array}{c}\text { Potential Source of } \\
\text { Competitive Advantage }\end{array}$} & \multicolumn{3}{|c|}{$\begin{array}{l}\text { Present Strength Relative } \\
\text { to Competitive Rivals }\end{array}$} & \multicolumn{3}{|c|}{$\begin{array}{l}\text { Future Importance to } \\
\text { Major Customers }\end{array}$} \\
\hline & Above & Equal & Below & High & Moderate & Low \\
\hline \multicolumn{7}{|l|}{ GENERAL } \\
\hline \multicolumn{7}{|l|}{ Company Image } \\
\hline \multicolumn{7}{|l|}{ Relative market share } \\
\hline \multicolumn{7}{|l|}{ Financial Strength } \\
\hline \multicolumn{7}{|l|}{ Profit Margin } \\
\hline \multicolumn{7}{|l|}{ Knowledge of market } \\
\hline \multicolumn{7}{|l|}{ Patents } \\
\hline \multicolumn{7}{|l|}{ Technological capability } \\
\hline \multicolumn{7}{|l|}{ Product promotion } \\
\hline \multicolumn{7}{|l|}{ Breadth of production line } \\
\hline \multicolumn{7}{|l|}{ Breadth of distribution } \\
\hline \multicolumn{7}{|l|}{ CUSTOMER SERVICE } \\
\hline \multicolumn{7}{|l|}{ Product availability } \\
\hline \multicolumn{7}{|l|}{ Order cycle time } \\
\hline \multicolumn{7}{|l|}{ Inquiry response time } \\
\hline \multicolumn{7}{|l|}{ Error in shipment } \\
\hline \multicolumn{7}{|l|}{ Damaged goods } \\
\hline \multicolumn{7}{|l|}{ Special services } \\
\hline \multicolumn{7}{|l|}{ After sales services } \\
\hline \multicolumn{7}{|l|}{ Consistency of service } \\
\hline \multicolumn{7}{|l|}{ QUALTY } \\
\hline Product reliability & & & & & & \\
\hline Product durability & & & & & & \\
\hline Conformance to specifications & & & & & & \\
\hline Product design & & & & & & \\
\hline Product features & & & & & & \\
\hline Ease of servicing product & & & & & & \\
\hline On-time delivery & & & & & & \\
\hline PRODUCTION TECHNIQUES & & & & & & \\
\hline Volume flexibility & & & & & & \\
\hline Quality programs & & & & & & \\
\hline Process control & & & & & & \\
\hline Material requirements planning & & & & & & \\
\hline Lead-time reduction & & & & & & \\
\hline Computer controlled machinen & & & & & & \\
\hline Computer aided design & & & & & & \\
\hline Restructured suppliers & & & & & & \\
\hline Automated material handling & & & & & & \\
\hline Worker participation programs & & & & & & \\
\hline Broad sharing of information & & & & & & \\
\hline PRICE & & & & & & \\
\hline OTHER & & & & & & \\
\hline
\end{tabular}


Companies that can enhance their competitive advantage are those that, in response to the threat of discontinuity or rapidly changing environmental factors:

a. are aware that changes are taking place;

b. are able to face the arenas that must be change - sometimes radically - and have the will to act;

c. are able to assess logically the various consequences for the company;

d. recognize that time and information are key resources and sources of distinctive competencies for the competitive struggle.

e. can develop an overall strong commitment, discipline, and focus for what the business is to do and how it will best do it;

f. can formulate a clear strategy based upon well-thought concepts of quality, efficiency, and customer service;

g. can mobilize the organization's resources through leadership, decisiveness, and communications, so that people at all levels within the organization, know, understand, and accept wholeheartedly the strategy;

h. is able to achieve full integration of functions and tasks across functional departments.

The integration of proactive marketing and manufacturing strategies is necessary to give a manufacturer the capability to move horizontally toward customers and to move downward to meet or exceed competitive benchmarks (See Figure 1). Mandated change cannot be faced by partial effort. Discontinuity is too serious a threat to survival not to be confronted by the holistic formulation and implementation of strategy.

Implementation of such a strategy will depend on activities that facilitate, encourage, and reward effective interaction among all functional areas. Information, influence, and support must flow abundantly among the functions of finance, research and development, engineering, manufacturing, and marketing. It will require managers in each area who regard the others as equals and capable of making strategic contributions to areas other than their own. It calls for managers with determination, vision, and the capacity to maintain a focused effort over a long time, and often in the face of organizational resistance.

\section{Conclusion}

There is a Chinese maxim: "Unless we change direction, we are likely to end up where we are headed." Manufacturers confronted by mandated change and the threat of discontinuity in the marketplace must change direction. A manufacturer may no longer say: "We make and sell what we are good at." The drastic transformation worldwide industry dramatically shows manufacturers that they must accept the view that what is "good" is determined by the present and future expectations of customers and the benchmarks set by worldwide competitors. Manufacturers are challenged to develop a new integration of perspective, thinking, shared values, leadership, and strategy. 
This paper proposes that the first steps in setting a new direction are: (a) an understanding of the ideas of mandated change and marketplace discontinuity, (b) an assessment of the manufacturers' current and future competitive position in terms of customer services, quality, and production methods, and (c) a commitment to the formulation and implementation of a plan of action that integrates marketing and manufacturing strategies.

The interrelationships and interdependencies between and among components of a manufacturer's business-level strategy, manufacturing strategy, and marketing strategy may be complex. Properly linked these components can enhance distinctive competencies and provide strategic opportunities.

A specific manufacturer seeking to move in a new direction will have to explore many subtle interrelationships peculiar to the business; these are not covered by this paper. Some of the questions which a specific situation may call to the fore are such as the following. How does a manufacturer confronting mandated change achieve both focus and flexibility? How does each of the building blocks of competitive advantage-targeted markets, the effective use of time and information as strategic resources, a new thrust toward human resource development, and a proactive manufacturing strategy-contribute to a firm's distinctive competencies? How may the concepts of customer orientation, product development and improvement, and distinctive competencies be quantified, so as to provide a sharper tool for the analysis of changes in competitive advantage? How is an assessment of customer service, quality, and production methods converted into effective action in the marketplace? These and related questions open areas for research in the strategic management of manufacturing firms.

While this paper does not attempt to answer the particular challenges facing a specific manufacturer, it may provide useful hints to one seeking competitive advantage while facing mandated change.

\section{References}

1. Bell, R.R. and Burnham, J.M. "The Paradox of Manufacturing Productivity and Innovation." Business Horizons, Vol. 32, No.5 (September/October, 1989).

2. Binstead, D. "Learning to Cope with Change." Management Decision, Volume 23 (November 3,1986 ).

3. Bogazzi, R.P. Principles of Marketing Management. Chicago, II: Science Research Associates, Inc. (1986), p. 215.

4. Camp, R.C. "Benchmarking: The Search for Industry Best Practices that Lead to Superior Performance." Quality Progress (March, 1989), pp. 76-82.

5. Connor, L. and Landry, P. "Workshop Report: JTT Purchasing at Xerox." Target, Volume 3, No. 4 (Winter, 1987).

6. Dumaine, B. "How Managers Can Succeed Through Speed." Fortune (February 13, 1989), pp. 54-59. 
7. Fortana, R.M. "Quality Function Deployment: Taking Quality Upstream." Target, Vol. 3, No. 4 (Winter, 1987), pp. 11-16.

8. Gorr, 1. "Cooper Tire: Successful Adaptation in a Changing Industry" The Journal of Business Strategy (Winter, 1987), pp. 83-86.

9. Jacobson, G. and Hillkirk, J. XEROX: An American Samurai. New York, NY: McMillan and Company (1986).

10. Jaikumar, R. "Post Industrial Manufacturing." Harvard Business Review, Vol. 64, No. 6 (November/December, 1986), pp. 69-76.

11. Jennings, D.F. and Lampken, J.R. "Insights into the Relationships Between Strategic Momentum and Environmental Scanning: An Empirical Analysis." Akron Business and Economic Review, Vol. 20, No. 1 (Spring, 1989), pp. 8493.

12. Miyamoto, M. Remarks at Conference sponsored by the Office for the Study of Automobile Transportation, University of Michigan, Ann Arbor, MI (April 6-8, 1989).

13. Morgan, G. Riding the Waves of Change: Developing Managerial Competencies for a Turbulent World. San Francisco, CA: Jossey-Bass Publishers (1988), pp. 37-41.

14. Parker, J.R. "Xerox Supplier Total Quality Strategy." Sixth Annual Conference of the Association for Manufacturing Excellence Proceedings, St. Louis, Mo. (1988), p. 2.

15. Ohmae, $\mathrm{K}$ The Mind of the Strategist. The Art of Japanese Business. New York, NY: McGraw-Hill Book Company (1982), pp. 62 et seq.

16. Porter, M.E. Competitive Strategy: Techniques for Analyzing Industries and Competitors. New York, NY: The Fall Press (1980), Chapter 1.

17. Porter, M.E. Op.Cit., Chapter 2.

18. Porter, M.E., and Miller, V.E. "How Information Gives You Competitive Advantage." Harvard Business Review, Vol. 63, No. 4 (July/August 1985), pp. 149-60.

19. Shapiro, B.P. “What the Hell is Market Oriented?" Harvard Business Review Vol. 66, No. 6 (November/December 1988), pp. 119-125.

20. Skinner, W. "The Productivity Paradox." Harvard Business Review, Vol. 64, No. 4 (July/ August, 1986), pp. 55-59.

21. Wheelwright, S.C. "Building Excellence in Manufacturing." In: Quality, Productivity, and Innovation (Ed. Shetty, Y.K. and Buehler, V.M.), Elsevier Science Publishing Co. Inc. (1987), pp. 341-362.

22. Zuboff, S. "New World of Computer-Mediated Work." Harvard Business Review, Vol. 60, No. 5 (September/October, 1982), pp. 142-151. 